\title{
Screening of Extraction Process and The Estimation of Total Alkaloids in Carica papaya Linn. Leaf
}

\author{
Sisca Devi, Meri Ropiqa, Yosi Bayu Murti, Akhmad Kharis Nugroho* \\ Faculty of Pharmacy, Universitas Gadjah Mada, Sleman, Yogyakarta, Indonesia
}

\begin{abstract}
The papaya leaf decoctions have been widely used as a traditional treatment for malaria. The alkaloid of papaya leaves, carpaine, is reported to have the antiplasmodial activity in vitro. The industrial-scale commercial product development requires the quantification of the carpaine, and total alkaloids in the papaya leave as the raw materials. This study aims to optimize the extraction process leading to the highest yield and total alkaloids. The extraction process was carried out using different methods and solvents. The first method was maceration with the water-miscible solvent of ethanol: distilled water: HCl 37\% (89: 10: $1 \mathrm{v} / \mathrm{v} / \mathrm{v}$ ). The second method was maceration with the water-immiscible solvent of dichloromethane solvents in $\mathrm{pH}$ 8-9 with ammonium hydroxide. The third method was digestion with acid water solvent of $0.05 \mathrm{~N} \mathrm{HCl}$. The identification of alkaloids employed the analysis using Thin Layer Chromatography (TLC) and Dragendroff reagent. The quantification of carpaine used a densitometer, while the spectrophotometric method was used to estimate the total alkaloids. The results showed that despite the extraction methods used, the tested extracts confirm the alkaloids content with the highest yield of 3.09\% (84.72\% of total alkaloids).
\end{abstract}

Keywords: Carica papaya Linn., total alkaloids, maceration, digestion

\section{INTRODUCTION}

Papaya (Carica papaya Linn.) grows in tropical regions such as Indonesia, and it is traditionally known to have many health benefits. Papaya leaf extract had shown good inhibitory activity on plasmodium Falcifarum (Kovendan et al., 2012). This condition was confirmed by Abdilah et al. (2015), who obtained the effective dose $\left(E_{50}\right)$ of $173.20 \pm 3.56 \mathrm{mg} / \mathrm{kg}$ body weight, through in vivo testing using mice. The antimalaria activity in the papaya leaf is derived from its carpaine compounds (Julianti et al., 2014).

The alkaloid in the papaya tissue is stored in the free-alkaline form. The extraction of alkaloid compounds can be done in several ways; extraction with water solvents, water-miscible solvents, and water-immiscible solvent (Kumar, 2014). Julianti et al. (2014) conducted a research to quantify carpaine alkaloid using several solvents. The research offered a conclusion that a high carpaine alkaloid yield was obtained, following additional ammonium solution. The solvent that helped to produce a high yield of extracts and carpaine alkaloids was maceration with petroleum ether. Wang et al. (2015) isolated carpaine using solvent maceration, i.e. ethanol: distilled water: $\mathrm{HCl} 37 \%$ ( 89: $10: 1 \mathrm{v} / \mathrm{v} / \mathrm{v}$ ). This step was followed by liquidliquid extraction with $n$-hexane, ammonium hydroxide addition to increase alkalinity,

\footnotetext{
*Corresponding author: Akhmad Kharis Nugroho Email : a.k.nugroho@ugm.ac.id
}

and fractionation with chloroform. These processes generated alkaloid carpaine amounted to $0.93 \mathrm{gram} /$ kilogram of dried simplicia. The isolation result of the research is not useful, especially for industrial-scale production. It is because it requires a large amount of solvent, a high purification stage, and it produces only a small yield. Therefore, it is necessary to optimize the extraction process to produce a high alkaloid yield.

\section{METHODOLOGY Materials}

Papaya leaves were obtained from Center for Research and Development of medicinal Plants and Traditional Medicine, Tawangmangu, Central Java. The chemicals used in this study were dichloromethane, ethanol 96\%, and distilled water (CV. Mandiri Surya, technical grade). The other chemicals were ammonium hydroxide, methanol, chloroform, bromocresol green, $\mathrm{HCl}, \mathrm{NaOH}$, sodium phosphate, citric acid, Dragendroff reagents, and Silica Gel 60 F254 plate (Merck, Germany, analytical grade).

\section{Methods}

\section{Extraction process}

First Extraction Method:

The first extraction was modified based on the method of Wang et al. (2015). First, a hundred grams of simplicia in the macerator were submerged by $600 \mathrm{~mL}$ of ethanol $96 \%$ : distilled water: $\mathrm{HCl} 37 \%$ (89:10:1). The maceration process 
Table I. Sensory Properties Of Extract In Various Extraction Methods

\begin{tabular}{cccc}
\hline $\begin{array}{c}\text { Extraction } \\
\text { Methods }\end{array}$ & Color of extract & Smell & Taste \\
\hline 1 & Dark brown & Papaya special smell & Bitter \\
2 & Black green & Papaya special smell & Bitter \\
3 & Dark brown & Papaya special smell & Bitter \\
\hline
\end{tabular}

was performed for $2 \times 24$ hours with occasional stirring. The macerated samples were then concentrated by using a vacuum rotary evaporator.

Second, the concentrated extract was fractionated with $n$-hexane solvent at a 1:1 ratio. The non-hexane fraction resulted in the previous process was then collected and alkalized with ammonium hydroxide to $\mathrm{pH}$ 8-9. It was followed by the addition of chloroform solvent with a 1:1 ratio. The chloroform fraction was then collected. The process was then repeated three times to produce the final chloroform fraction. Finally, the fraction was evaporated using a vacuum rotary evaporator.

\section{Second Extraction Method:}

The method involved maceration at room temperature. A hundred grams of simplicia in the macerator were submerged by $600 \mathrm{~mL}$ of dichloromethane. The mixture was then alkalinized by adding ammonium hydroxide to the $\mathrm{pH}$ of 8-9. The maceration was performed for 4 hours with occasional stirring. The macerated samples were then concentrated by using a vacuum rotary evaporator.

\section{Third Extraction Method:}

This method involved digestion extraction. A hundred grams of simplicia in the infusion pan were submerged by $1,000 \mathrm{~mL}$ of distilled water. The mixture was then added with $0.05 \mathrm{~N} \mathrm{HCl}$ to reach a $\mathrm{pH}$ of 2-3. The digestion was performed for 15 minutes after the pan reached $70^{\circ} \mathrm{C}$. The macerate was filtered in hot conditions. The macerate was then alkalinized by adding ammonium hydroxide to the $\mathrm{pH}$ of 8-9. It was followed by fractionation of dichloromethane solvent at a 1:1 ratio. The dicloromethane fraction resulted from the previous process was then collected. Finally, the fraction was evaporated using a vacuum rotary evaporator.

\section{Determining the thin-layer chromatography (TLC) profile}

The thin-layer chromatography method used silica gel 60F 254 as the stationary phase and dichloromethane solution: methanol: ammonium hydroxide (95: 5: $20 \mu \mathrm{L}$ ) as the mobile phase. The identification of the alkaloid was performed using the Dragendroff reagents.

Quantification of carpaine and total alkaloids

The analysis of carpaine implemented a densitometry method with an isolated standard. The calculation of total alkaloid extract referred to the report of Salamah and Ningsih (2017) as well as Patel et al. (2015), employing the spectrophotometric method based on the reaction between alkaloid and bromocresol green (BCG).

\section{RESULTS AND DISCUSSION}

The papaya leaves (Carica papaya Linn.) used in this study were in the form of dried simplicia with the moisture content of $6.60 \%$. The simplicia were obtained from Center for Research and Development of medicinal Plants and Traditional Medicine, Tawangmangu, Central Java. The selection of the sample was carefully conducted to avoid unrepresentative chemical compositions. In this study, several types of extraction methods were applied using various types of solvents. For each extraction method, a hundred grams of dried simplicia papaya leaves were used. The extract yield value was calculated from the percentage of extract weight divided by dried simplicia weight. The yield of papaya leaves extract based on the extraction process is presented in Figure 1. The results of the sensory properties of the extract are shown in Table I.

In this study, the highest extract yield was obtained from the extraction in the second method with the dichloromethane solvent. The solvents used for the first and third methods were more polar than dichloromethane. In the second method, significant yields derived from chlorophyll or impurities were dissolved in dichloromethane. The first and third methods had followed by the removal of impurities and purification, resulting in a low yield. This study found that the isolates yield was smaller than the one obtained by Wang et al. (2015). The result thereof might be due to the differences in the origin of the used plants.

The TLC profile determination used the mobile phase of dichloromethane-methanol (95: 5 $\mathrm{v} / \mathrm{v}$ ) with the addition of ammonium hydroxide and the stationary phase of TLC silica gel 60 F254. 


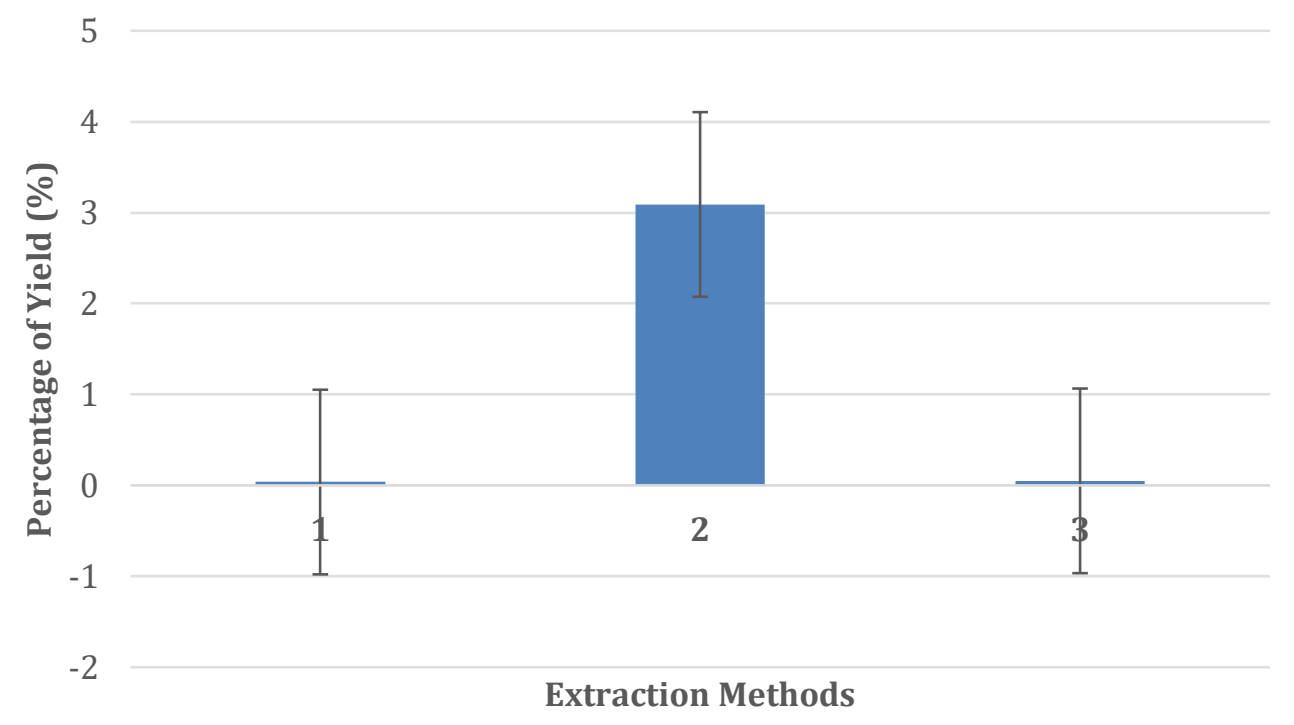

Figure 1. Percentage Of Yield Extract In Various Extraction Methods

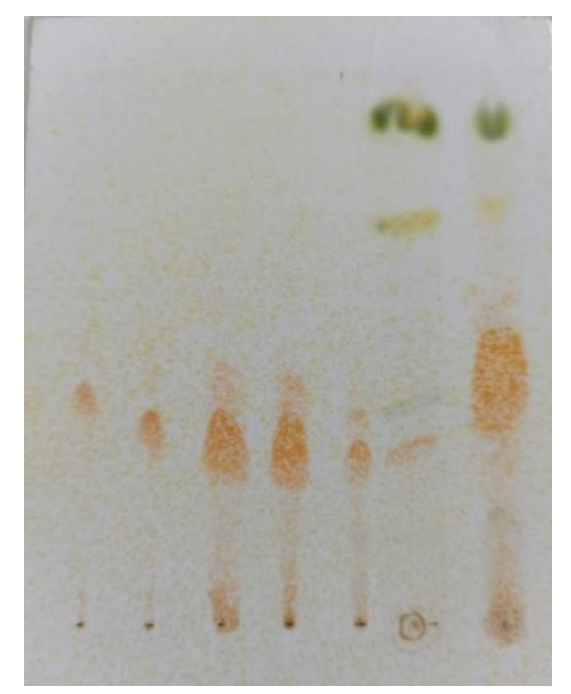

Figure 2. TLC profile

The TLC profile in various extraction methods confirmed the presence of the alkaloid, indicated by the orange-brown spots in TLC after the Dragendroff reagents spraying. The two orangecolored spots from the first method indicated the impurities of the compound. The second and third methods produced green and yellow spots, indicating the similar condition. The third method had a more intense orange color with wider spot area, compared to the first and the second methods.

The next phase was the quantification of carpaine using a densitometer. TLC densitometry is a quantitative analysis method that is simple, accurate, precise, easy, suitable for routine quality control (Misra et al., 2008). The wavelength for the detection of carpaine isolate at the densitometer was evaluated from the scanning of 200-700 nm alkaloid compounds (Sushmitha et al., 2018). The scanning results showed that the maximum wavelength produced was $501 \mathrm{~nm}$. The TLC profile is presented in Figure 2. The TLC measure using the densitometer started by spotting variation of the isolate to figure out the calibration curve and linear regression. Figure 3 shows the estimation of carpaine measured using the three related methods.

Meanwhile, the spectrophotometric method was used to estimate the total alkaloids. The analysis involved a complex reaction between bromocresol green and alkaloid at a pH of 4.6. In this process, the extract was added with 


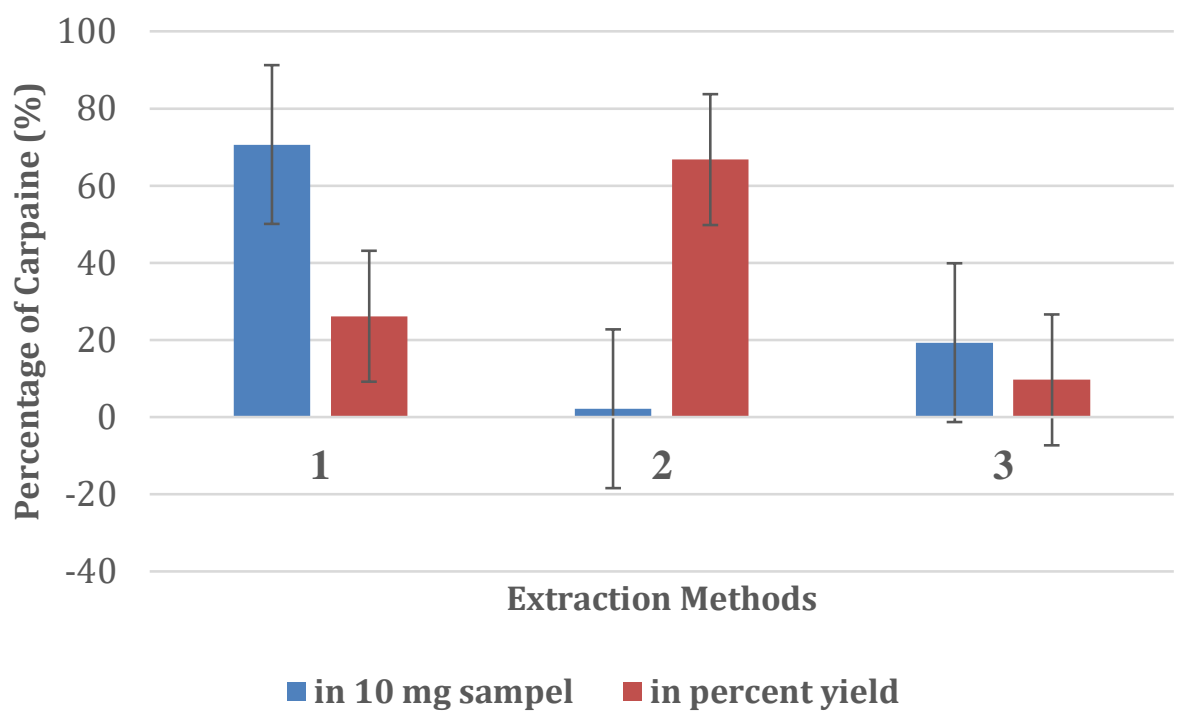

Figure 3. Percentage of carpaine in various exctraction methods with densitometer

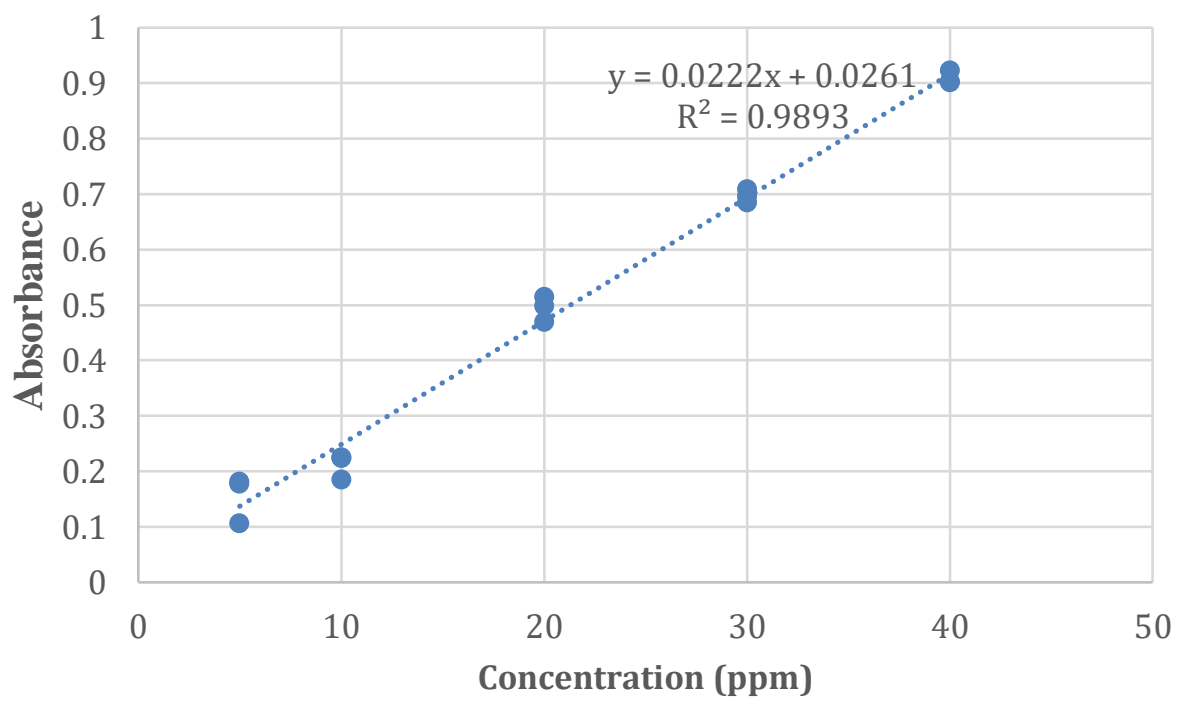

Figure 4. Calibration curve and linear regression of isolate as standard

chloroform. The chloroform phase was then measured at a wavelength of $414 \mathrm{~nm}$. The isolate was used as the standard, and its variations of concentration taken were $5,10,20,30$, and 40 $\mathrm{ppm}$. The results of the calibration curve and linear regression, and the calculation of the total alkaloid by three methods were shown in Figure 4 and Figure 5. The analysis of the spectrophotometry method enabled the counting of all alkaloids in the samples, which reacted with bromocresol green, although it was not exclusive of carpaine. The densitometric method could measure carpaine, which had the same retention value as standard isolate.

The highest of the total alkaloid content was obtained by the first method. This situation is due to the ethanol maceration process, which attracts alkaloids and free alkaloids. The acidic condition during maceration also increased the solubility of alkaloid salts. The advantage of this method is the presence of fewer impurities, such as polysaccharides or soluble proteins (Yubin et al., 2014). The first extraction method attracted fatsoluble compounds. 


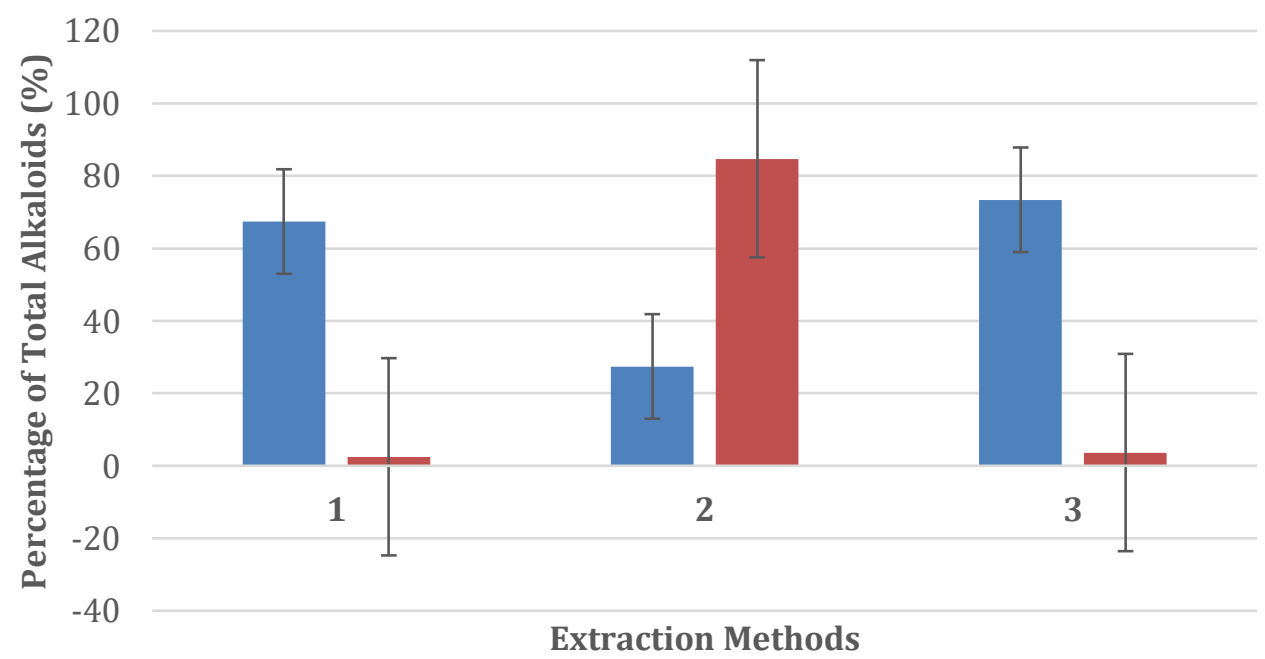

घ in $10 \mathrm{mg}$ sampel $\quad$ in percent yield

Figure 5. Percentage of total alkaloid in various extraction methods using the spectrophotometric method

As a consequence, in the following process, the macerate had to be extracted with $n$-hexane to remove that impurity of fat-soluble compounds. Then, the extract was alkalinized to change the form of the alkaloid salt into a free alkaloid in $\mathrm{pH} 8$ 9. The free alkaloid could bind chloroform so that it was separable from the non-chloroform phase. The purification process was conducted three times to maximize the removal of impurities and the yields of carpaine. While such a process could last for a long time, the extract yield would not endure, resulting in a low amount of yield.

The maceration with dichloromethane in the second method can attract all of the free alkaloids (Kumar, 2014; Yubin et al., 2014). However, this method can also attract other impurities such as chlorophyll and other fatsoluble impurities. Consequently, the extract yield might be high, but the alkaloid yield would be less. In the third method, the extraction process was carried out using acid digestion in a water solvent at a boiling state. The boiling condition could speed up the diffusion process. The acidic water solvent could attract alkaloids in the form of dissolvable salt. This method also can attract large number of other plant components (e.g., chlrophylls, starches, tannins, proteins). As a consequence, in the following process, the macerate had to be extracted using $n$-hexane to remove that plant components. Then finally, the alkaloids in the form of dissolvable salt should be converted into free alkaloids prior to the chloroform extraction.
Therefore, the second method (i.e. the maceration extraction using dichloromethane solvent) is the best of papaya leaves extraction.

\section{CONCLUSION}

Based on the results, all of the extraction methods confirm the alkaloids content of Carica papaya Linn. The second method has the highest yield of alkaloids content at 3.09\% (84.72\% of total alkaloids).

\section{ACKNOWLEDGEMENT}

This research was funded by The Master Thesis Research Grant of Indonesian Ministry of Education Directorate General of Higher Education the year of 2019 .

\section{REFERENCES}

Abdillah, S., Tambunan, R.M., Farida, Y., Sandhiutami, N.M.D., Dewi, R.M., 2015, 'Phytochemical screening and antimalarial activity of some plants traditionally used in Indonesia', Asian Pac. J. Trop. Dis, 5, 454457.

Julianti, T., Oufir, M., Hamburger, M., 2014, 'Quantification of the Antiplasmodial Alkaloid Carpaine in Papaya (Carica papaya) Leaves', Planta Med, 80, 1138-1142.

Kovendan, K., Murugan, K., Panneerselvam, C., Aarthi, N., Kumar, P.M., Subramaniam, J., Amerasan, D., Kalimuthu, K., Vincent, S., 2012, 'Antimalarial activity of Carica papaya 
(Family: Caricaceae) leaf extract against Plasmodium falciparum', Asian Pac. J. Trop. Dis, 2, 306-311.

Kumar, S., 2014, 'Alkaloidal Drugs A Review', AJPST, 4(3), 107-119.

Misra, H., Mehta, B.K., Jain, D.C., 2008, 'Optimization of Extraction Conditions and HPTLC - UV Method for Determination of Quinine in Different Extracts of Cinchona species Bark', Rec.Nat.Prod, 2, 107-115.

Patel, R.K., Patel, J.B., Trivedi, P.D., 2015, 'Spektrophotometric Method For The Estimation of Total Alkaloids In The Tinospora Cordifolia M. And ITS Herbal Formulation', Int J Pharm Pharm Sci 7, 3.

Salamah, N., Ningsih, D.S., 2017, 'Total alkaloid content in various fractions of
Tabernaemonata sphaerocarpa Bl. (Jembirit) leaves', IOP Conf. Ser. Mater. Sci. Eng., 259, 012017.

Sushmitha, H.S., Rajesh, V., Madappa, M.B., Sthyamurthy, B., 2018, 'A Comparative Study On Characterisation of Various Extracts of Carica papaya Leaves', EJPMR, 5, 401-407.

Wang, X., Hu, C., Ai, Q., Chen, Y., Wang, Z., Ou, S., 2015, 'Isolation and Identification Carpaine in Carica papaya L. Leaf by HPLC-UV Method', Int. J. Food Prop, 18, 1505-1512.

Yubin, J., Miao, Y., Bing, W., Yao, Z., 2014, 'The extraction, separation and purification of alkaloids in the natural medicine', JOCPR, 6 , 338-345 